\title{
Menstrual Needs and Associations with Sexual and Reproductive Risks in Rural Kenyan Females: A Cross-Sectional Behavioral Survey Linked with HIV Prevalence
}

\author{
Penelope A. Phillips-Howard, PhD, ${ }^{1,2}$ George Otieno, MSc, ${ }^{2}$ Barbara Burmen, MBChB, MPH, ${ }^{2}$ \\ Frederick Otieno, $\mathrm{MPH}^{2,3}$ Frederick Odongo, MSc, ${ }^{2}$ Clifford Odour, BSc, ${ }^{2}$ Elizabeth Nyothach, MA, ${ }^{2}$ \\ Nyanguara Amek, PhD, ${ }^{2}$ Emily Zielinski-Gutierrez, DrPH, ${ }^{4}$ Frank Odhiambo, PhD, ${ }^{2}$ Clement Zeh, PhD, \\ Daniel Kwaro, MBChB, MPH, Lisa A. Mills, MD, and Kayla F. Laserson, DSc ${ }^{6}$
}

\begin{abstract}
Background: Females in low and middle income countries (LMICs) have difficulty coping with menstrual needs, but few studies have examined the social or health implications of these needs.

Methods: Responses from 3418 menstruating females aged 13-29 years were extracted from an HIV and behavioral risks cross-sectional survey conducted in rural western Kenya. We examined sanitary products used, provision of products from sexual partners or from transactional sex, and demographic and sexual exposures. Results: Overall, $75 \%$ of females reported using commercial pads and $25 \%$ used traditional materials such as cloth or items like paper or tissue, with $10 \%$ of girls $<15$ years old depending on makeshift items. Two-thirds of females with no education relied on traditional items. Having attended secondary school increased the odds of using commercial pads among married (adjusted odds ratios [AOR] 4.8, 95\% confidence interval [CI] 3.257.12) and single females (AOR 2.17, 95\% CI 1.04-4.55). Married females had lower odds of pad use if they reported early $(<12$ years of age) compared with later $(\geq 18$ years) sexual debut $(64 \%$ vs. $78 \%$, AOR $0.45,95 \%$ CI 0.21-0.97). Two-thirds of pad users received them from sexual partners. Receipt was lower among married females if partners were violent (AOR 0.67, 95\% CI 0.53-0.85). Receipt among single females was higher if they had two or more sexual partners in the past year (AOR 2.11,95\% CI 1.04-4.29). Prevalence of engaging in sex for money to buy pads was low (1.3\%); however, $10 \%$ of 15 -year-olds reported this, with girls $\leq 15$ having significantly higher odds compared with females over 15 (AOR 2.84, 95\% CI 0.89-9.11). The odds of having transactional sex for pads was higher among females having two or more partners in the past 12 months (AOR 4.86, 95\% CI 2.06-11.43).

Conclusions: Menstrual needs of impoverished females in rural LMICs settings likely leads to increased physical and sexual harms. Studies are required to strengthen knowledge and to evaluate interventions to reduce these harms.

Introduction

$\mathbf{M}$ ENSTRUATION IS A NORMAL bodily function, affecting a quarter of the worlds' population. Menstrual management is a fundamental human right, yet cultural customs

and practices and lack of resources prevent girls and women from dealing with their menstrual needs with dignity. 1,2 Females in low and middle income countries (LMIC) have difficulty coping with menstrual needs due to lack of money or resources, forcing them to either accept suboptimal care

\footnotetext{
${ }^{1}$ Department of Clinical Sciences, Liverpool School of Tropical Medicine, Liverpool, United Kingdom.

${ }^{2}$ Kenya Medical Research Institute, Centre for Global Health Research, Kisumu, Kenya.

${ }^{3}$ Nyanza Reproductive Health Society, Kisumu, Kenya.

${ }^{4}$ Division of Global HIV and AIDS and ${ }^{5}$ Division of HIV/AIDS Prevention, Centers for Disease Control and Prevention, Kisumu, Kenya.

${ }^{6}$ Division of Global Health Protection, Center for Global Health, Centers for Disease Control and Prevention, Atlanta, Georgia.
}

(c) Penelope A. Phillips-Howard, et al. 2015; Published by Mary Ann Liebert, Inc. This Open Access article is distributed under the terms of the Creative Commons Attribution Noncommercial License (http://creativecommons.org/licenses/by-nc/4.0/) which permits any noncommercial use, distribution, and reproduction in any medium, provided the original author(s) and the source are credited.
\end{abstract}


or seek alternative ways of sourcing materials. ${ }^{3}$ Coping with menstrual care with dignity is further compromised in LMICs with a lack of water, hygiene, and sanitation (WASH) facilities, ${ }^{3-5}$ with women and girls self-reporting higher rates of reproductive tract infections such as vaginal discharge and itching in association with poor WASH conditions. ${ }^{6,7}$ Laboratory studies confirming associations are pending, however. ${ }^{8}$ Menstrual behavior and women's strategies to cope with menstrual needs differ by age and culture. ${ }^{9-11}$ Menstrual product use has been poorly documented in Africa, ${ }^{12}$ with information on this gleaned mainly while testing new products ${ }^{13,14,15}$ or while examining women's behaviors in preparation for microbicide trials. These findings suggest a paucity of options for impoverished females, where traditionally old cloths have been used, ${ }^{7,13}$ with a variety of other items used, such as cotton wool, grass, socks, plastic, and paper, especially among adolescent girls. ${ }^{16,17}$ Seemingly, only the most privileged have access to commercial pads. ${ }^{7,13,16-20}$ A number of qualitative studies have demonstrated the needs of schoolaged girls in LMICs, describing humiliating leakage and odor, which prevent girls from fully engaging while in school. $^{16-18,21}$

Schoolgirls' narratives indicate one method to obtain sanitary pads is by having sex to gain money to purchase pads, ${ }^{17,18,28}$ increasing their exposure to sexual and reproductive health risks. Studies have examined associations between transactional sex and sexual and reproductive health risks, such as human immunodeficiency virus (HIV) transmission and prevalence. ${ }^{22-24}$ However, quantitative evidence on the interrelationship between women and girls' menstrual needs and whether these needs increase their vulnerability is sparse. ${ }^{1,7,25}$ Documentation on the sourcing of menstrual products by women and girls, and if this is associated with sexual and reproductive health exposures would inform preventive programs, and solutions avoiding such risks could contribute to a number of the post-2015 sustainable development goals. $^{26}$

In rural western Kenya, a "menstrual feasibility study" tested the acceptability, use, and safety of menstrual cups and sanitary pads against "traditional practice" among primary school girls. ${ }^{5,17,27,28}$ Qualitative follow-up in the study confirm baseline findings that commercial sanitary products are highly valued, and some girls without access will resort to (or are coerced into) having sex to pay for sanitary products. ${ }^{17,27}$ However, no data are available on the general norms within the wider population to examine the prevalence and whether it is a behavior clustered among young girls reaching menarche. The study area has the highest prevalence of HIV among females nationally, which rises rapidly during adolescence, ${ }^{29}$ and intimate partner violence is endemic. ${ }^{30} \mathrm{~A}$ large cross-sectional HIV and sexual risk behaviors survey was conducted prior to the girls' menstrual feasibility study at the same study site. We gathered information on girls and women's use of sanitary items including commercial pads, how products were sourced, and whether these behaviors were associated with key demographic characteristics, and reported sexual and reproductive health indicators generated from this survey. We hypothesize females place value on commercial sanitary items and this necessity, within an impoverished setting, may be associated with their sexual exposures.

\section{Materials and Methods}

\section{Study design}

This was a menstrual needs and product sourcing study nested within a cross-sectional household survey evaluating the prevalence and sexual behavior risk correlates of HIV within a rural population under the Kenya Medical Research Institute (KEMRI)/Centers for Disease Control and Prevention (CDC) Health and Demographic Surveillance System (HDSS). ${ }^{31}$

\section{Study site and population}

The area under study lies within the HDSS, in Gem District, Siaya Country, about $20 \mathrm{~km}$ from Lake Victoria in western Kenya. ${ }^{31}$ Residents are almost exclusively of the Luo tribe, mostly Christian, and are mainly farmers and fisherfolk. ${ }^{31,32}$ Triannual census surveys are conducted through the HDSS, which generates annual factsheets on demographic and health indicators. In 2010 in Gem, the midyear population was 82,798 people living in 25,641 households, which are grouped by extended families into 14,501 compounds. Around half $(52.5 \%)$ the total population was female, of whom $22 \%$ were females of childbearing age (15-49 years), with a fertility rate of $4.2 \%$. The life expectancy at birth for females was estimated to be 53 years. The area typifies the disease burden of rural African communities, with high exposure to endemic HIV. ${ }^{31}$ HIV disproportionately affects females, with rates among girls rising rapidly between the ages of 16 and 17 years. ${ }^{29}$ Mortality among adolescents and young females ( 15 to 24 years of age) is mostly attributed to HIV ${ }^{33}$ but both all-cause and HIV-attributed mortality rates among all females have fallen as treatment and care services in the region has expanded. ${ }^{34}$

\section{Household HIV testing and behavioral survey}

The HIV service uptake and risk behaviors survey was administered in 2011-2012 in Gem. A community-based simple random survey approach was used. The KEMRI/CDC HDSS sampling frame of all registered compounds (14,501 in 2010) in Gem was used. First sampling was conducted as a community participatory event. All compound numbers, per village, were printed by ID number onto small pieces of paper. All chief/assistant chiefs, some village elders, 10 village reporters, and other opinion leaders (totaling 25) were invited to a community sampling meeting and asked to pick 30 compound numbers each from a bucket that had 14,501 pieces of paper representing all the Gem HDSS compounds identified in the last 2010 HDSS census. A total of 750 compounds were picked by the community. Second random sampling was conducted by the study statistician via computer, picking random numbers until a total sampling frame of $\sim 6,000$ compounds were identified. All persons aged 13 years and above residing in these compounds were invited to participate. The survey was conducted in two phases. Phase one targeted 10,000 respondents and phase two targeted 5,000 respondents. Trained field staff visited each compound and identified all individuals over 13 years of age in the home who had slept there the prior night. All eligible persons were verbally informed about the study, and if in agreement then provided written consent; as above, parental consent was required for minors ( $<15$ years, not married or had a child) 
who assented. Interviews took place privately in the home. A precoded structured questionnaire was used, and administered using a computer-assisted personal interview. Sexual and reproductive risk questions of relevance for this study, among female respondents, included ever had sexual intercourse, age at sexual debut, number of lifetime partners and number in the past 12 months, ever pregnant and pregnant in the past 12 months, ever experienced forced sex, and experienced sexual partner violence in the past 12 months. We took the opportunity to utilize this platform to add questions regarding what type of sanitary items girls and women used, if these were obtained from their sexual partner or through transactional sex for money to purchase items, and whether they had sexual intercourse during menstruation. Demographic questions asked included gender, age, level of schooling achieved, current marital status, occupation, and source of income.

Home-based HIV testing and counselling was offered to all participants in their homes; persons 18 years and older provided informed consent, and teenagers 13-17 years provided consent if they were mature minors (living with consensual sexual partner or female adolescent who was pregnant or a mother). For nonmature minors, parental consent and child assent was required. Individually and in a confidential manner, $0.5 \mathrm{cc}$ of blood was taken by a finger stick for rapid HIV antibody testing, performed by a counselor with training in HIV testing and counselling. Rapid HIV testing was done according to the National AIDS/STD Control Program algorithm using two parallel HIV rapid tests (Determine ${ }^{\mathrm{TM}}$, Abbott Laboratories, United States) and Bioline ${ }^{\mathrm{TM}}$ (Standard Diagnostics, Kyonggi-do, Korea) with a tie-breaker test for discordant results (Uni-gold ${ }^{\mathrm{TM}}$, Trinity Biotech, Ireland). ${ }^{35}$ The participant was given the results of the HIV test immediately in the home, together with risk reduction counseling for both HIV positives and negatives. Those found to have HIV infection were provided with education about HIV care and treatment, as well as a referral note for free HIV care and treatment services. The test results were entered into a scannable form that did not record the person's name or age, only the study identifier.

The cross-sectional survey collecting behavioral data as well as the HIV testing was designed to be conducted concurrently during home-based testing and counselling. The initial design of the study did not specify whether questionnaire or testing would be first; however, after $\sim 5 \%$ of the sample had been surveyed, questionnaire administration was standardized to be conducted first, before the HIV test. While the majority of participants were thereafter tested and counselled after the questionnaire, some participants requested to have the test conducted on a later date, and some requested to have the test prior to questionnaire completion. The median elapsed time between interview and testing was 6 days.

\section{Definitions and data handling}

Menstrual hygiene questions were "What type of sanitary wear do you use for your periods?" This provided a number of options, which were collapsed for multivariate analysis into use or nonuse of branded (commercial) pads, with the denominator all menstruating female survey participants. Two separate questions on sex partner-related acquisition of sanitary products were, "Has your sex partner ever bought you pads to look after your periods?" and "Have you ever had sex with someone to get money to buy items to take care of your periods?" These were treated as dichotomous variables of yes or no, with the denominator being all females reporting they were sexually active (yes to ever had sexual intercourse; $n=2,721)$, and with demographic and menstrual question responses $(n=2,715)$.

Our study sample was restricted to young women below 30 years, ${ }^{24}$ at heightened risk of HIV acquisition. Age was categorized using standard thresholds, ${ }^{36}$ as child (girl) (age $<15$ years), adolescent (15-19 years), and young adult (20-24 years), with the residual (25-29 years) representing mature adults. Each yearly age band contributed an average $6 \%$ (range 5\%-8\%) to the study population except $<15$ years, which were thus pooled. Educational attainment was collapsed into attended secondary and above versus (only) attended primary or none. Marital status of married, widowed, divorced, or single was collapsed into ever married versus single. The number of sexual partners in the past 12 months was aggregated into a dichotomous variable of $0-1$ and 2 or more partners based on analysis showing a median and mode of 1 in each age category, and a mean of 1.06 (standard deviation 0.30). Main source of financial resources/income was collapsed into "family" and "other." Females answering yes to "Have you ever had sexual intercourse? (By sexual intercourse we mean sex that involves a penis being inserted inside a vagina or anus)" are described, for the purposes of this study, as sexually active.

\section{Data analysis}

The survey data file was imported into SPSS (v21 release) for cleaning and transforming. We extracted data on all girls and women below the age of 30 years who reported menstruating for this analysis $(n=3,418)$. Pearson's chi-squared tests were used to compare categorical outcomes and MannWhitney U tests were used to compare continuous outcomes, as these outcomes were not normally distributed. Significance was set at 0.05 . Multivariate analysis was conducted using log binomial analyses, with adjusted odds ratios (AOR), 95\% confidence intervals (CI), and Wald chisquared. The dependent variables were commercial pad use, provision of sanitary items from sexual partners, and obtained money from sex to purchase items. We explored associations with demographic and sexual exposures. All variables where data were provided systematically by all participants were selected first (thus, condom use was excluded as these were gathered in a limited subsample). Twoway interactions for demographic variables were tested for each of the three predictor models. All nonsignificant twoway interactions were removed. Marriage interacted significantly with other variables. Thus, models for commercial pad use and pad provision by sexual partners are shown separately for married and nonmarried participants. The education and age interaction was also significant and composite variable was created. Past-year pregnancy and sexual violence ever were excluded as nonpredictive (menstrual experience would be minimal during pregnancy/lactation, and sexual violence "ever" was collinear to past 12 months physical violence but lacked sensitivity). No interactions occurred with sex for pads but the low prevalence necessitated 
restricting variables included in the model. All final models exclude HIV status as test results were unavailable for $\sim 40 \%$ causing instability of the models, and inclusion found HIV to be insignificant in each of the models.

\section{Ethical considerations}

The study was approved by KEMRI and CDC Institutional Review Boards. Written informed consent (assent for minors, with parental consent) was obtained to participate in the study and to undergo home based HIV testing and counselling.

\section{Results}

\section{Overall demographics and sexual risk behaviors}

The refusal rate was $4.7 \%(192 / 4,117)$ among females $<30$ years approached, and 8.6\% $(439 / 5,089)$ among females 30 years and older. Analysis was restricted to the 3,418 menstruating girls and young women below the age of 30 years (Table 1). The median age of females was 21 years (interquartile range [IQR] 18-25 years). A quarter of females had completed primary education, with a further quarter attaining some secondary education (Table 1). Over half (57\%) of the females were currently married. Other than students (26\%), females' main occupations were farming, small business (i.e., selling maize), or unemployed. Nearly half of females received income from work, while a third depended on income from their family. Among the 3,418 menstruating females, $80 \%(2,721)$ were sexually active (Table 1$)$. The median age of sexual debut was 16 years (IQR 14-17). The mean number of sexual partners in the past 12 months was 1.06 (SD 0.30). Among the sexually active, 35\% reported pregnancy in the past 12 months. Overall, 14\% of girls and women reported "ever forced" to have sex and $15 \%$ reported physical harm from sexual partners in the past 12 months. Females reporting past year physical violence had a 2-fold higher odds of reporting ever forced sex compared with no physical violence $(24.2 \%$ vs. $12.3 \%$; OR $1.96,95 \%$ CI 1.60 2.40). The prevalence of HIV diagnosed by test procedures was $11 \%$, rising with age (chi-squared linear trend $=92$, $<0.001$ ), from $1 \%$ in 15 year olds, $5 \%$ in 19 year olds, $13 \%$ in 24 year olds, to $20 \%$ in 29 year olds.

\section{Use of commercial or traditional items and associations with demographic and sexual exposures}

Three-quarters of females reported having used commercial (branded) sanitary pads, while $25 \%$ relied on traditional items such as cloth, tissue or other makeshift materials, with highest prevalence in the youngest and older females (Table 1). No females reported use of insertable items such as tampons or menstrual cups. One in five $(22 \%)$ girls $<15$ years old used cloth/rags from the house, with $10 \%$ having no access to cloth, relying instead on impromptu makeshift items such as tissues, or bedding. Use of traditional items was particularly high $(62 \%)$ among those with no education, while nine in ten reaching secondary education or with professional or business careers reported commercial pad use. Among sexual exposures, use of traditional items was highest in those reporting younger sexual debut, sex during menstruation, and a positive HIV status (Table 1). Highest prevalence of commercial pad use was among those reporting two or more sexual partners in the past year.
In multivariate analysis, ever married females $<20$ years old had a 2-fold higher odds of using commercial pads compared with older females (Table 2). Married women with secondary education had more than a 4-fold higher odds of using pads [AOR 4.8, 3.25-7.12 (reciprocal from Table 2)]. Among single females, older age and higher education were also associated with pad use but significance was less than for married females (Table 2). Associations between commercial pad use and sexual exposures were only significant among married women. Use was significantly higher among females reporting older age at sexual debut; showing a strong linear effect, rising from $61 \%$ if age was $<12$ years to $79 \%$ if age was 18 years or older (chi-squared linear trend 20.8; $p<0.001$ ) (Table 2). Married females reporting no physical violence from a sexual partner had higher odds of pad use. HIV status was not associated with commercial pad use for married or unmarried females in multivariate analysis.

\section{Pad provision by sexual partners and associations with demographic and sexual exposures}

Of the $75 \%$ of females reporting use of commercial pads, two-thirds reported their sexual partner had provided them with pads. Of all sexually active participants, half $(51.7 \%)$ reported that their sexual partner had provided them with their sanitary pads, with a higher odds of ever married compared with single females reporting this (OR 1.12, 95\% CI 1.031.23). Among married females, the prevalence of pad provision by their sexual partner was highest among older women achieving secondary education $(75 \%)$ and lowest for the least older uneducated $(49 \%)$ (Table $3 ; p<0.001)$. Among singles, young uneducated were least likely to be provided compared with older married although not significantly different $(47 \%$ vs. $54 \% ; p=0.54)$. Associations of pad provision with sexual exposures held in multivariate analysis, with ever married women who reported having sex during menstruation or having a violent partner significantly less likely to receive pads. The earlier the sexual debut, the lower the odds of females receiving pads, with those commencing debut at $<12$ years of age being 2 -fold less likely than those starting at 18 years or older (AOR 0.45, 95\% CI 0.21-0.97). HIV status was not associated with provision of sanitary pads by a sexual partner for married or unmarried females.

\section{Sex for money for pads and associations with demographic and sexual exposures}

While the overall prevalence of reported sex for money to purchase sanitary items among sexually active participants was very low (1.3\%), this was clustered among younger girls, with $10 \%$ of 15 year olds reporting this. The odds in younger aged girls $\leq 15$ years compared with older females was 6 -fold higher in bivariate analysis and remained significantly higher in multivariate analysis, (7.1\% vs. $1.1 \%$; AOR 2.84, $95 \%$ CI 0.89-9.11; Table 4). Married females had significantly lower odds of sex for money for pads compared with single females (AOR 0.39, 95\% CI 0.16-0.97). Females reliant on family income were at higher odds of reporting sex for money for items compared with those reliant on other sources (Table 4). Reporting more than one sexual partner in the past 12 months was the only sexual exposure retained in the model with a significant effect (AOR 4.86, 95\% CI 2.06-11.43). HIV status was not associated with sex for money. 
Table 1. Characteristics of Young ( $<30$ Years Old) Menstruating Women in Rural Kenya Reporting Use of Commercial Pads or Traditional Materials

\begin{tabular}{|c|c|c|c|c|c|c|}
\hline \multirow[b]{2}{*}{ Characteristics } & \multirow[b]{2}{*}{$\mathrm{N}$} & \multirow[b]{2}{*}{ Values } & \multirow[b]{2}{*}{$\mathrm{n}(\%)$} & \multicolumn{2}{|c|}{ Type of menstrual item used } & \multirow[b]{2}{*}{$\begin{array}{c}\text { Significance } \\
\chi^{2} ; \mathrm{p}\end{array}$} \\
\hline & & & & $\begin{array}{l}\text { Commercial } \\
\text { pads, n (\%) }\end{array}$ & $\begin{array}{c}\text { Traditional } \\
\text { items, }^{\text {a }} \text { n (\%) }\end{array}$ & \\
\hline \multirow{2}{*}{$\begin{array}{l}\text { Full sample } \\
\text { Sociodemographic } \\
\text { Age (years) }\end{array}$} & 3,418 & All & $3,418(100)$ & $2,576(75.4)$ & $842(24.6)$ & \\
\hline & 3,418 & $\begin{array}{l}<15 \\
15-19 \\
20-24 \\
25-29\end{array}$ & $\begin{array}{c}167(4.9) \\
1,134(33.2) \\
1,116(32.7) \\
1.001(29.3)\end{array}$ & $\begin{array}{l}112(67.1) \\
925(81.6) \\
861(77.2) \\
678(67.7)\end{array}$ & $\begin{array}{r}55(32.9) \\
209(18.4) \\
255(22.8) \\
323(32.3)\end{array}$ & $63.0 ;<0.001$ \\
\hline \multirow[t]{4}{*}{ Education } & 3,418 & $\begin{array}{l}\text { None } \\
\text { Primary } \\
\text { incomplete }\end{array}$ & $\begin{array}{c}58(1.7) \\
1,599(46.8)\end{array}$ & $\begin{array}{r}22(37.9) \\
1,067(66.7)\end{array}$ & $\begin{array}{r}36(62.1) \\
532(33.3)\end{array}$ & $240 ;<0.001$ \\
\hline & & $\begin{array}{l}\text { Primary complete } \\
\text { Secondary } \\
\text { incomplete }\end{array}$ & $\begin{array}{l}914(26.7) \\
587(17.2)\end{array}$ & $\begin{array}{l}706(77.2) \\
536(91.3)\end{array}$ & $\begin{array}{c}208(22.8) \\
51(8.7)\end{array}$ & \\
\hline & & $\begin{array}{l}\text { Secondary } \\
\text { complete }\end{array}$ & $198(5.8)$ & $185(93.4)$ & $13(6.6)$ & \\
\hline & & Tertiary & $62(1.8)$ & $60(96.8)$ & $2(3.2)$ & \\
\hline \multirow[t]{3}{*}{ Marital status } & 3,412 & $\begin{array}{l}\text { Single } \\
\text { Married }\end{array}$ & $\begin{array}{l}1,351(39.6) \\
1,700(55.9)\end{array}$ & $\begin{array}{l}1,118(82.8) \\
1,346(70.5)\end{array}$ & $\begin{array}{l}233(17.2) \\
563(29.5)\end{array}$ & $84.7 ;<0.001$ \\
\hline & & $\begin{array}{l}\text { Divorced or } \\
\text { separated }\end{array}$ & $78(2.3)$ & $67(85.9)$ & $11(14.1)$ & \\
\hline & & Widowed & $74(2.2)$ & $40(54.1)$ & $34(45.9)$ & \\
\hline \multirow[t]{9}{*}{ Occupation } & 3,417 & $\begin{array}{l}\text { Farmer } \\
\text { Profession (e.g., }\end{array}$ & $\begin{array}{c}742 \text { (21.7) } \\
77(2.3)\end{array}$ & $\begin{array}{r}480(64.7) \\
69(89.6)\end{array}$ & $\begin{array}{r}262(35.3) \\
8(10.4)\end{array}$ & $93.7 ;<0.001$ \\
\hline & & $\begin{array}{l}\text { Small business } \\
\text { (e.g., sell } \\
\text { maize) }\end{array}$ & $558(16.3)$ & $397(71.1)$ & $161(28.9)$ & \\
\hline & & $\begin{array}{l}\text { Business owner } \\
\text { (e.g., kiosk) }\end{array}$ & $37(1.1)$ & $33(89.2)$ & $4(10.8)$ & \\
\hline & & $\begin{array}{r}\text { Skilled labour } \\
\text { (e.g., tailor) }\end{array}$ & $131(3.8)$ & $108(82.4)$ & $23(17.6)$ & \\
\hline & & $\begin{array}{l}\text { Unskilled labour } \\
\text { (e.g., shamba) }\end{array}$ & $51(1.5)$ & $39(76.5)$ & $12(23.5)$ & \\
\hline & & Unemployed & 731 (21.4) & $563(77.0)$ & $168(23.0)$ & \\
\hline & & Student & $881(25.8)$ & 729 (82.7) & $152(17.3)$ & \\
\hline & & Homemaker/wife & $195(5.7)$ & 147 (75.4) & $48(24.6)$ & \\
\hline & & Other & $14(0.4)$ & 11 (78.6) & $3(21.4)$ & \\
\hline \multirow[t]{4}{*}{ Source of income } & 3,412 & None & 644 (18.9) & $484(75.2)$ & $160(24.8)$ & $39.5 ;<0.001$ \\
\hline & & Work & $1,530(44.8)$ & $1,084(70.8)$ & $446(29.2)$ & \\
\hline & & Sexual partner & $81(2.4)$ & 70 (86.4) & 11 (13.6) & \\
\hline & & Family & 1,157 (33.9) & 933 (80.6) & $224(19.4)$ & \\
\hline \multirow{2}{*}{ Source of income } & 3,412 & Other & $2,255(66.1)$ & $1,638(72.6)$ & 617 (27.4) & $16.4 ;<0.001$ \\
\hline & & Family & 1,157 & 933 (80.6) & $224(19.4)$ & \\
\hline \multirow[t]{2}{*}{ Ever had sex } & 3,417 & Yes & 2,721 (79.6) & $2,024(74.4)$ & 697 (25.6) & $6.8 ; 0.009$ \\
\hline & & No & $696(20.4)$ & $551(79.2)$ & $145(20.8)$ & \\
\hline \multirow[t]{2}{*}{$\begin{array}{l}\text { Pregnant past } 12 \\
\text { months }\end{array}$} & 3,418 & Yes & 949 (27.8) & 679 (71.5) & $270(28.5)$ & $10.3 ; 0.001$ \\
\hline & & No & $2,469(72.2)$ & $1,897(76.8)$ & $572(23.2)$ & \\
\hline \multirow{4}{*}{$\begin{array}{l}\text { Sex debut age } \\
\text { (years) }^{b}\end{array}$} & 2,619 & $<12$ & $45(1.7)$ & $30(66.7)$ & $15(33.3)$ & $26.1 ;<0.001$ \\
\hline & & $12-14$ & $655(25.0)$ & $456(69.6)$ & $199(30.4)$ & \\
\hline & & $15-17$ & $1,392(53.2)$ & $1,041(74.8)$ & $351(25.1)$ & \\
\hline & & & $527(20.1)$ & $433(82.2)$ & $94(17.8)$ & \\
\hline \multirow[t]{2}{*}{ Menstrual sex ${ }^{b}$} & 2,718 & Yes & $192(7.1)$ & $121(63.0)$ & $71(37.0)$ & $13.9 ;<0.001$ \\
\hline & & No & $2,526(92.9)$ & $1,900(75.2)$ & $626(24.8)$ & \\
\hline \multirow{2}{*}{$\begin{array}{l}\text { Sex partners in }<12 \\
\text { months }\end{array}$} & 2,406 & $\geq 2$ & $136(5.7)$ & $116(85.3)$ & $20(14.7)$ & $9.6 ; 0.002$ \\
\hline & & $0-1$ & $2,270(94.3)$ & $1,663(73.3)$ & $607(26.7)$ & \\
\hline
\end{tabular}


TABle 1. (CONTINUED)

\begin{tabular}{|c|c|c|c|c|c|c|}
\hline \multirow[b]{2}{*}{ Characteristics } & \multirow[b]{2}{*}{$\mathrm{N}$} & \multirow[b]{2}{*}{ Values } & \multirow[b]{2}{*}{$\mathrm{n}(\%)$} & \multicolumn{2}{|c|}{ Type of menstrual item used } & \multirow[b]{2}{*}{$\begin{array}{c}\text { Significance } \\
\chi^{2} ; \mathrm{p}\end{array}$} \\
\hline & & & & $\begin{array}{l}\text { Commercial } \\
\text { pads, n (\%) }\end{array}$ & $\begin{array}{l}\text { Traditional } \\
\text { items, }{ }^{a} \text { n (\%) }\end{array}$ & \\
\hline $\begin{array}{l}\text { Ever sexual } \\
\text { violence }\end{array}$ & 2,721 & Yes & $388(14.3)$ & $285(73.5)$ & $103(26.5)$ & $0.21 ; 0.65$ \\
\hline $\begin{array}{l}\text { Sexual partner } \\
\text { violent }\end{array}$ & 2,671 & $\begin{array}{l}\text { No } \\
\text { Yes }\end{array}$ & $\begin{array}{r}2,333(85.7) \\
414(15.5)\end{array}$ & $\begin{array}{r}1,739(74.5) \\
276(66.7)\end{array}$ & $\begin{array}{l}594(25.5) \\
138(33.3)\end{array}$ & $14.9 ;<0.001$ \\
\hline HIV test ${ }^{d}$ & 2,112 & $\begin{array}{l}\text { No } \\
\text { HIV+ } \\
\text { HIV- }\end{array}$ & $\begin{array}{c}2,257(84.5) \\
184(8.7) \\
1,928(91.3)\end{array}$ & $\begin{array}{r}1,705(75.5) \\
112(60.9) \\
1,412(73.2)\end{array}$ & $\begin{array}{r}552(24.5) \\
72(39.1) \\
516(26.8)\end{array}$ & $12.8 ;<0.001$ \\
\hline
\end{tabular}

${ }^{\mathrm{a}}$ Traditional materials include cloth, tissues, paper, locally made or other makeshift items.

${ }^{\mathrm{b}}$ Among those reporting as sexually active $(n=2,721)$.

${ }^{c}$ Partner violence determined by response to question, "Has your sexual partner in the past year hit/slapped/kicked or done anything else to hurt you physically?"; restricted to those with partner.

${ }_{\mathrm{d}} \mathrm{HIV}$, human immunodeficiency virus; among females tested only.

\section{Discussion}

This large cross-sectional study contributes toward a currently sparse literature on what sanitary products girls and women living in impoverished settings use and how they source these items. Our study notes a number of associations between sanitary product sourcing and demographic and sexual exposures. A quarter of females questioned used traditional items rather than commercial pads. This was significantly higher among young girls aged $<15$ years and the oldest females (25-29 years) studied. Overall, one in 10 young girls without pads did not even have access to old cloth. In the separate (later) menstrual study in the same area, schoolgirls reported the need to search for any makeshift items they could find, ranging from paper, tissue, foam from mattress, cotton wool, or grass, as cloth was not available in the house or was restricted for use by the mother. ${ }^{17}$ Similar findings are reported from a five-country African study, reporting girls may even resort to cow dung, goat skin, or by digging holes to expel menstrual flow. ${ }^{37}$ Among the five countries, between $17 \%$ (South Sudan) and 24\% (Ethiopia) of girls could access pads. ${ }^{37}$ Further, it is likely girls in our current study will report pad use, even if infrequently used, as lack of access (due to poverty) shames girls. ${ }^{16,17}$

A series of qualitative studies provide narratives describing the humiliating leakage and odor girls experience if they cannot adequately manage their menstruation in school. ${ }^{16-18}$ Girls describe how "other girls" engage in sex for money to buy pads. ${ }^{17,28}$ In our study, the prevalence of sex for money to purchase pads was reportedly very low $(<2 \%)$, but prevalence was 6-fold higher among girls of 15 years or younger, with a clustering (10\% prevalence) among 15 year olds. Our data show single and married women experience different exposures, for single women, lacking resources for menstrual care increased their vulnerability to sexual coercion, while married women have access to sanitary products through their spouse or sexual partner. Single, uneducated, poorer girls depending on their family for any money were at higher odds of having sex to buy pads, with these girls reporting more than one sexual partner over the past year. Such behaviors increase young girls' exposure to other sexual and reproductive harms, such as pregnancy, which affects girls' ability to stay in school, ${ }^{38,39}$ and HIV, which rises rapidly among girls in this population. ${ }^{29}$ The low prevalence of sex for buying pads may be an underestimate due to girls' reticence to admit this; in a separate secondary schoolgirl study, girls described this as a common event among classmates (Phillips-Howard, unpublished data). Interventions to assist young impoverished girls' access to menstrual care in LMIC thus has the potential to reduce their exposure to sexual harms as well as improve their wellbeing and experience in school.

Use of good quality materials are also important for adult women, with our data showing associations between young adult women's sourcing of menstrual products and sexual exposures. Pad use in this population appears higher than elsewhere. Studies exploring antimicrobial interventions ${ }^{7,22}$ and potential options for new menstrual products ${ }^{13,15}$ provide some comparative data. In Zimbabwe, $28 \%$ of women reported using cloth and $54 \%$ cotton wool, with only $16 \%$ reporting pad use in the past year. ${ }^{13}$ In Tanzania, $60 \%$ of women reported using cloth in the past 3 months, with only $15 \%$ reporting use of pads. ${ }^{7}$ Minimal pad use in Tanzanian and Zimbabwean women may reflect the study population, who were older and had limited resources. In our current study, nonuse of commercial pads was greatest among widowed women and with those with minimal education- $-62 \%$ of women with no education reported using traditional items. Using the larger survey population from which we abstracted data in females $<30$ years of age, we found $54 \%$ of women aged 30-49 years reported use of traditional items, double that of the females $<30$ years we included in our study. A study examining acceptability of different sanitary products in urban South African women attending a reproductive health clinic, likely to be educated and less impoverished, reported that $92 \%$ used pads, $20 \%$ tampons, and only $6 \%$ cloth at baseline. ${ }^{15}$

Studies illustrate the value schoolgirls place on pads for dignified menstrual care in school. ${ }^{16-18,28}$ The relatively high cost of commercial pads competes against other needed items in the family budget, resulting in sexual risk-taking, as girls have no cash of their own. ${ }^{17,28} \mathrm{~A}$ study examining acceptability of menstrual cups found $67 \%$ of Zimbabwean women reported at least once having no money to purchase a sanitary product in the previous year. ${ }^{13}$ In an area of India with a low 


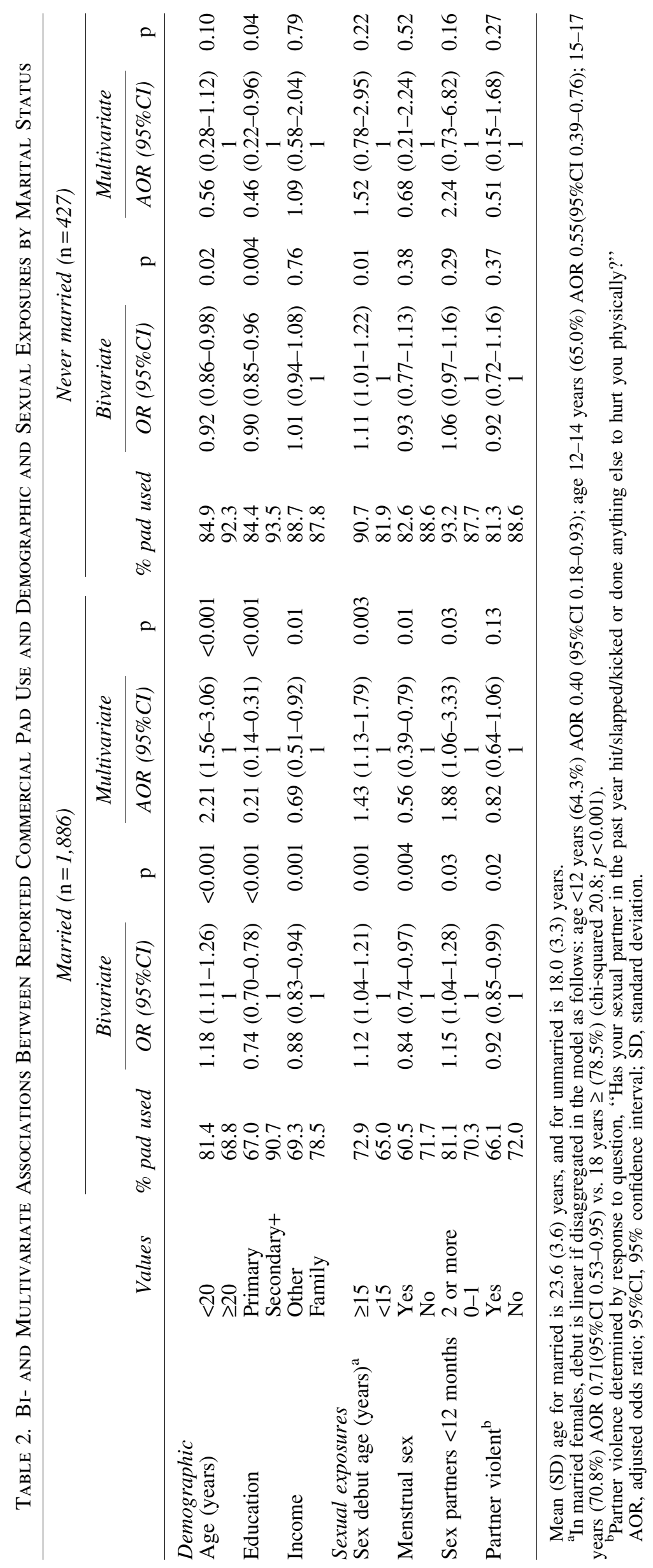




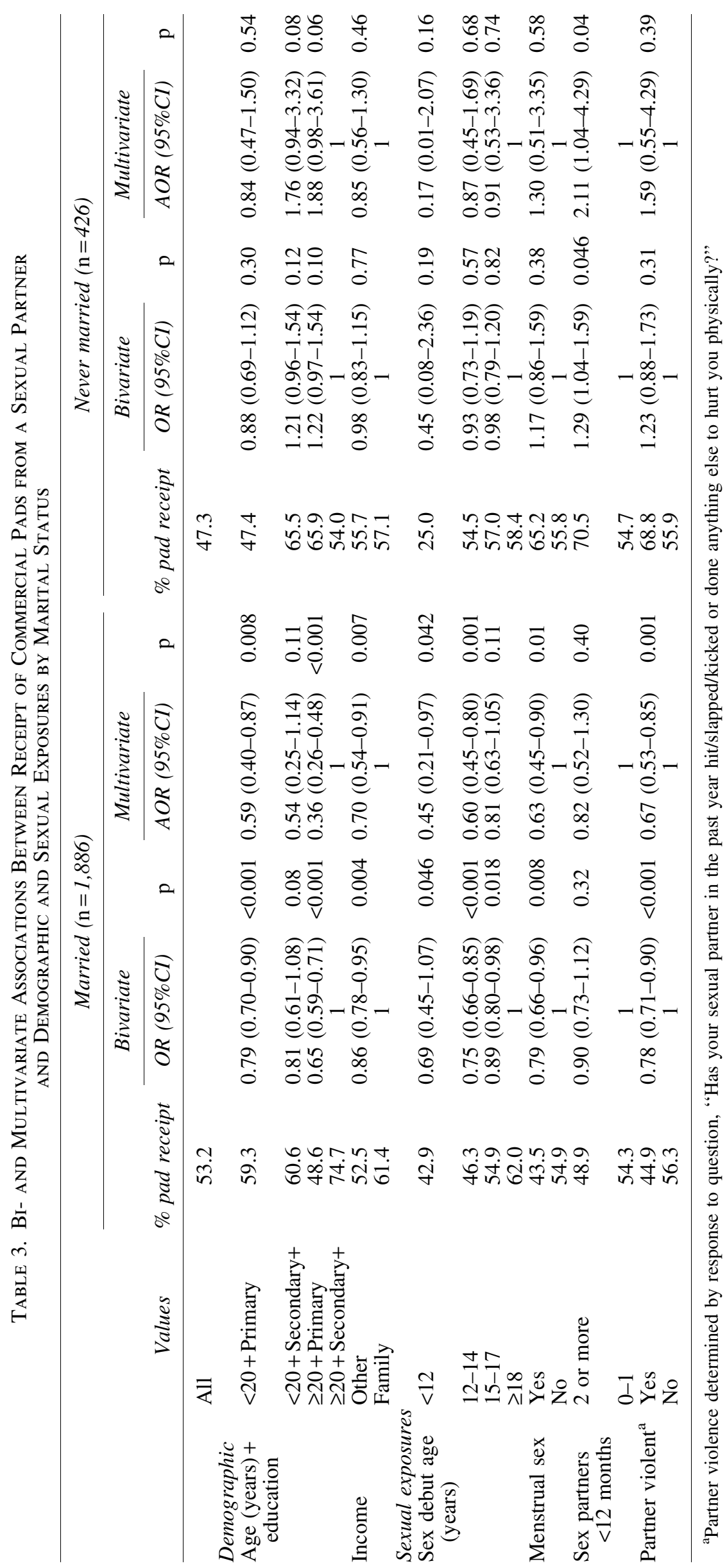


Table 4. Bi- and Multivariate Associations Between Reported Sex for Money for Pads and Demographic and Sexual Exposures in Young Menstruating Females in Rural Kenya

\begin{tabular}{|c|c|c|c|c|c|c|}
\hline & \multirow[b]{2}{*}{ Values } & \multirow[b]{2}{*}{ Sex for money (\%) } & Bivariate & \multirow[b]{2}{*}{$\mathrm{p}$} & \multirow{2}{*}{$\begin{array}{c}\text { Multivariate } \\
\text { AOR }(95 \% C I)\end{array}$} & \multirow[b]{2}{*}{$\mathrm{p}$} \\
\hline & & & OR $(95 \% C I)$ & & & \\
\hline Demooranhic & All & 1.3 & & & & \\
\hline $\begin{array}{l}\text { Demographic } \\
\text { Age (years) }\end{array}$ & $\begin{array}{l}\leq 15 \\
>15\end{array}$ & $\begin{array}{l}7.1 \\
1.1\end{array}$ & $6.44(2.34-17.84)$ & $<0.001$ & $\begin{array}{c}2.84(0.89-9.11) \\
1\end{array}$ & 0.08 \\
\hline Ever Married & $\begin{array}{l}\text { Yes } \\
\text { No }\end{array}$ & $\begin{array}{l}0.8 \\
3.4\end{array}$ & $0.23\left(\begin{array}{c}0.11-0.46) \\
1\end{array}\right.$ & $<0.001$ & $0.39 \begin{array}{c}(0.16-0.97) \\
1\end{array}$ & 0.04 \\
\hline Education & $\begin{array}{l}<\text { Primary } \\
\text { Secondary }+\end{array}$ & $\begin{array}{l}1.1 \\
1.8\end{array}$ & $\begin{array}{c}0.62(0.29-1.35) \\
1\end{array}$ & 0.23 & $\begin{array}{c}0.94(0.41-2.13) \\
1\end{array}$ & 0.88 \\
\hline Source money & $\begin{array}{l}\text { Other } \\
\text { Family }\end{array}$ & $\begin{array}{l}0.8 \\
3.0\end{array}$ & $\begin{array}{c}0.25(0.13-0.52) \\
1\end{array}$ & $<0.001$ & $0.40(0.18-0.91)$ & 0.03 \\
\hline $\begin{array}{l}\text { Sexual exposures } \\
\text { Sex partners }<12 \text { months }\end{array}$ & $\begin{array}{l}2 \text { or more } \\
0-1\end{array}$ & $\begin{array}{l}5.9 \\
1.0\end{array}$ & 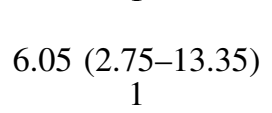 & $<0.001$ & $\begin{array}{c}4.86(2.06-11.43) \\
1\end{array}$ & $<0.001$ \\
\hline
\end{tabular}

No interactions detected, so model not stratified by marital status, and age and education not combined.

(29\%) prevalence of sanitary pad use, only a quarter of women aged $15-45$ years, were willing to pay US $\$ 0.01$ cost for sanitary pads. ${ }^{40}$ In our study area the most commonly used brand costs $\sim \$ 1$ per pack of 8 . Assuming two packs per cycle, this would cost an individual \$24 per year, with a lifetime (35-year) cost of $\$ 840$. For females in rural areas, this is an added burden to families struggling to survive on a low wage. Our study area is one of the poorest of Kenya, with $63 \%$ of the population living on less than $\$ 1.0$ a day. ${ }^{41}$

Sexual and reproductive health programs for adolescents and young adults thus need to guide and support provision of affordable and valued sanitary products for menstrual care or cash for girls to buy their own. In our separate menstrual feasibility study, schoolgirls said the provision of free pads and menstrual cups reduced girls' need to seek money for pads through sex; ${ }^{28}$ however, the preventive effect of providing sanitary care or cash to cover menstrual care needs to be confirmed through formal trials. A recent acceptability trial in 105 South African women tested menstrual cups over three menstrual cycles, finding women preferred cups to tampons and pads in terms of comfort, quality, menstrual blood collection, and appearance. ${ }^{15}$

The menstrual cup is a potential cost-effective alternative to pads. Cups, typically made of silicone, have been tested among high income populations for safety and effectiveness, ${ }^{42,43}$ and among small populations of girls and women in LMICs, ${ }^{13,15,28,44}$ with over 20 brands now available for use globally. Used as an insertable receptacle to retain menstrual flow, emptied and then reinserted, cups have gained interest among researchers for females in low income countries, ${ }^{13}$ with small-scale acceptability studies demonstrating females' interest and willingness to try them. ${ }^{13,28,44}$ Cup price varies, ranging from $\$ 10$ to $\$ 40$, with a cup lasting a maximum of 10 years, but assuming half this in LMICs settings, a menstrual lifetime ( $\sim 35$ year) cost would range between $\$ 70$ and $\$ 280$ per person. Further studies examining the value, hygienic safety, impact, and cost-effectiveness of such products in a variety of cultural settings are thus merited.

This study has a number of limitations. Data were generated from a cross-sectional survey and only inferences on associations can be made without ascribing causality; for example, the relationship between lower provision of pads and partner violence could be cause or effect. We added questions on menstruation to an existing questionnaire; while a variety of sexual behaviors were captured, there were limitations on the number of additional questions that could be asked and we could not probe further. We acknowledge, as with all behavioral surveys, that a portion of respondents may have not provided complete information. Selection by reported sexual activity may cause some bias, particularly among the youngest aged females; however, the prevalence of sexual exposures appear comparable to other studies and sites. Interviewers were trained to be attentive to respondents concerns, with privacy assured per individual respondent. While only a small proportion of persons (either $\sim 5 \%$ early in the study, or specifically requested) had the HIV test before the questionnaire, we note that knowledge of their HIV status may have influenced their answers about their sexual behaviors. Although large numbers were surveyed $(15,243$ in total), sample selection specific for this analysis (menstruating young women $<30$ years old), reduced the sample to 3,418 . Further, modelling on sanitary product use and sourcing associated with sexual exposures only examined associations among females who reported sexual intercourse, with a number of questions only asked if respondents stated they were sexually active. Caution is suggested in interpreting the data provided, and particularly for analyses on low prevalence behaviors such as sex for money for sanitary products. We hope this study nevertheless adds to a limited body of data and ignites interest in this neglected topic. Further studies within the identified vulnerable risk categories are required.

\section{Acknowledgments}

Members of Gem community are thanked for their participation. Field staff, data managers, and laboratory and administrative staff are thanked for their assistance. We are very grateful to Deborah Gust, Division of HIV/AIDS Prevention at the Centers for Disease Control and Prevention, Atlanta, for reviewing the manuscript. KEMRI/CDC HDSS is a member of the International Network for the Demographic Evaluation of 
Populations and Their Health in Developing Countries (INDEPTH) Network. Funding for the HIV study came from the Division of HIV/AIDS Prevention, Centers for Disease Control and Prevention, Atlanta, and from the Division of Global HIV and Aids through President's Emergency Plan for AIDS Relief (PEPFAR) funds to KEMRI. The Director of KEMRI has approved this manuscript. PPH, EN, CO, and FO were partially funded by a UK-Joint Global Health Trials award for the menstrual feasibility study. The findings and conclusions in this paper are those of the authors and do not necessarily represent the official position of the Centers for Disease Control and Prevention.

This work was conducted as part of the Kenya Medical Research Institute (KEMRI) and Centers for Disease Control and Prevention (CDC) Collaboration.

\section{Author Disclosure Statement}

No competing financial interests exist.

\section{References}

1. Johnston-Robledo I, Chrisler J. The menstrual mark: Menstruation as social stigma. Sex Roles 2013;1:9-18.

2. Severy LJ, Thapa S, Askew I, Glor J. Menstrual experiences and beliefs: A multicountry study of relationships with fertility and fertility regulating methods. Women Health 1993; 20:1-20.

3. Sommer M, Kjellén M, Chibesa Pensulo C. Girls' and women's unmet needs for menstrual hygiene management (MHM): The interactions between MHM and sanitation systems in low-income countries. J Water Sanit Hyg Dev 2013;3:283-297.

4. Sahin M. Guest editorial: Tackling the stigma and gender marginalization related to menstruation via WASH in schools programmes. Waterlines 2015;34. DOI: 10.3362/1756-3488 .2015.001,

5. Alexander K, Oduor C, Nyothach E, et al. Water, sanitation and hygiene conditions in Kenyan rural schools: Are schools meeting the needs of menstruating girls? Water 2014;6:1453-1466.

6. Khanna A, Bhawsar R. Menstrual practices and reproductive problems: A study of adolescent girls in Rajasthan. J Health Manag 2005;7:91-107.

7. Allen CF, Desmond N, Chiduo B, et al. Intravaginal and menstrual practices among women working in food and recreational facilities in Mwanza, Tanzania: Implications for microbicide trials. AIDS Behav 2010;14:11691181 .

8. Morison L, Ekpo G, West B, et al. Bacterial vaginosis in relation to menstrual cycle, menstrual protection method, and sexual intercourse in rural Gambian women. Sex Transm Infect 2005;81:242-247.

9. Gauset $\mathrm{Q}$. The cognitive rationality of taboos on production and reproduction in sub-saharan Africa. Africa 2002;72: 628-654.

10. Marvan ML, Islas M, Vela L, Chrisler JC, Warren EA. Stereotypes of women in different stages of their reproductive life: Data from Mexico and the United States. Health Care Women Int 2008;29:673-687.

11. Dunnavant N, Roberts T. Restriction and renewal, pollution and power, constraint and community: The paradoxes of religious women's experiences of menstruation. Sex Roles 2012;68:121-131.
12. Bobel C. "Our Revolution Has Style": Contemporary menstrual product activists "doing feminism" in the third wave. Sex Roles 2006; 54:331-345.

13. Averbach S, Sahin-Hodoglugil N, Musara P, Chipato T, van der Straten A. Duet for menstrual protection: A feasibility study in Zimbabwe. Contraception 2009;79:463-468.

14. Farage M, Elsner P, Maibach H. Influence of usage practices, ethnicity and climate on the skin compatibility of sanitary pads. Arch Gynecol Obstet 2007;275:415-427.

15. Beksinska ME, Smit J, Greener R, et al. Acceptability and performance of the menstrual cup in South Africa: A randomized crossover trial comparing the menstrual cup to tampons or sanitary pads. J Womens Health (Larchmt) 2015; 24:151-158.

16. McMahon SA, Winch PJ, Caruso BA, et al. 'The girl with her period is the one to hang her head' Reflections on menstrual management among schoolgirls in rural Kenya. BMC Int Health Hum Rights 2011;11:17.

17. Mason L, Nyothach E, Alexander K, et al. 'We Keep It Secret So No One Should Know' A qualitative study to explore young schoolgirls experiences with menstruation in rural western Kenya. PLoS One 2013;8:e79132.

18. Sommer M. Where the education system and women's bodies collide: The social and health impact of girls' experiences of menstruation and schooling in Tanzania. J Adolesc 2010;33:521-529.

19. Ahmed R, Yesmin K. Menstrual hygiene: Breaking the silence. In: Wicken J, Verhagen J, Sijbesma C, Da Silva C, Ryan P, eds. Beyond construction: Use by all. A collection of case studies from sanitation and hygiene promotion practitioners in South Asia. London: WaterAid, 2008:283287.

20. Vallely A, Fitzgerald L, Fiya V, et al. Intravaginal practices and microbicide acceptability in Papua New Guinea: Implications for HIV prevention in a moderate-prevalence setting. BMC Res Notes 2012;5:613.

21. Thakur H, Aronsson A, Bansode S, Lundborg CS, Dalvie S, Faxelid E. Knowledge, practices and restrictions related to menstruation among young women from low socioeconomic community in Mumbai, India. Front Public Health 2014;2:2-7.

22. Lees S, Desmond N, Allen C, Bugeke G, Vallely A, Ross D. Sexual risk behaviour for women working in recreational venues in Mwanza, Tanzania: Considerations for the acceptability and use of vaginal microbicide gels. Cult Health Sex 2009;11:581-595.

23. Meekers D, Calves AE. 'Main' girlfriends, girlfriends, marriage, and money: The social context of HIV risk behaviour in sub-Saharan Africa. Health Transit Rev 1997;7 Suppl:361-735.

24. Harling G, Newell ML, Tanser F, Kawachi I, Subramanian SV, Barnighausen T. Do age-disparate relationships drive HIV incidence in young women? Evidence from a population cohort in rural KwaZulu-Natal, South Africa. J Acquir Immune Defic Syndr 2014;66:443-451.

25. Stubbs M, Kernoff Mansfield P. Our menses, ourselves: Research and commentary from The Society for Menstrual Cycle Research. Sex Roles 2006;54:311-313.

26. United Nations (UN) Working Group of the General Assembly on Social Development Goals. Open Working Group proposal for Sustainable Development Goals. Document A/68/970. New York: United Nations, 2014.

27. Phillips-Howard P. Menstrual solutions in adolescent schoolgirls in western Kenya: An acceptability, feasibility 
and safety study (tools and instruments). In: Sommer, Marni, Emily Vasquez, Nancy Worthington, Murat Sahin and Therese Dooley, WASH in Schools Empowers Girls' Education: Proceedings of the Menstrual Hygiene Management in Schools Virtual Conference 2013, United Nations Children's Fund and Columbia University, New York, 2014.

28. Mason L, Laserson K, Oruko K, et al. Adolescent schoolgirls' experiences of menstrual cups and pads in rural western Kenya: A qualitative study. Waterlines 2015;34: 15-30. DOI: 10.3362/1756-3488.2015.003.

29. Amornkul PN, Vandenhoudt H, Nasokho P, et al. HIV prevalence and associated risk factors among individuals aged 13-34 years in Rural Western Kenya. PLoS One 2009;4: E6470.

30. Kenya National Bureau of Statistics (KNBS). Kenya demographic and health survey 2008-09. Calverton, MD: KNBS and ICF Macro, 2010.

31. Odhiambo FO, Laserson KF, Sewe M, et al. Profile: The KEMRI/CDC Health and Demographic Surveillance SystemWestern Kenya. Int J Epidemiol 2012;41:977-987.

32. Cohen D, Atieno Odhiambo E. Siaya, the historical anthropology of an African landscape. London: James Curry, 1989.

33. Phillips-Howard PA, Odhiambo FO, Hamel M, et al. Mortality trends from 2003 to 2009 among adolescents and young adults in rural western Kenya using a health and demographic surveillance system. PLoS One 2012;7: e47017-e47017.

34. Gargano JW, Laserson K, Muttai H, et al. The adult population impact of HIV care and antiretroviral therapy in a resource poor setting, 2003-2008. AIDS 2012;26:15451554.

35. Bigogo G, Amolloh M, Laserson KF, et al. The impact of home-based HIV counseling and testing on care-seeking and incidence of common infectious disease syndromes in rural western Kenya. BMC Infect Dis 2014;14:376.

36. Patton GC, Coffey C, Sawyer SM, et al. Global patterns of mortality in young people: A systematic analysis of population health data. Lancet 2009;374:881-892.
37. Tamiru S, Mamo K, Acidria P, Mushi R, Ali CS, Ndebele L. Towards a sustainable solution for school menstrual hygiene management: Cases of Ethiopia, Uganda, SouthSudan, Tanzania, and Zimbabwe. Waterlines 2015;34:92_102.

38. Grant M, Hallman K. Pregnancy-related school drop-out and prior school performance in south Africa. Population Council Policy Reserach Division Working Paper no. 212. New York: Population Council, 2006.

39. Hargreaves JR, Morison LA, Kim JC, et al. The association between school attendance, HIV infection and sexual behaviour among young people in rural South Africa. J Epidemiol Community Health 2008;62:113-119.

40. Misra P, Upadhyay RP, Sharma V, Anand K, Gupta V. A community-based study of menstrual hygiene practices and willingness to pay for sanitary napkins among women of a rural community in northern India. Natl Med J India 2013; 26:335-337.

41. CARE. Community initiatives for Child Survival Siaya (CICSS-II): Detailed implementation plan. CARE Kenya, submitted to USAID/BHR/PVC, 2000.

42. Howard C, Rose CL, Trouton K, et al. FLOW (finding lasting options for women): Multicentre randomized controlled trial comparing tampons with menstrual cups. Can Fam Physician 2011;57: E208-E215.

43. Stewart K, Greer R, Powell M. Women's experience of using the Mooncup. J Obstet Gynaecol 2010;30:285-287.

44. Oster E, Thornton R. Determinants of technology adoption: Peer effects in menstrual cup up-take. J Eur Econ Assoc 2012;10:1263-1293.

Address correspondence to: Penelope A. Phillips-Howard, PhD Department of Clinical Sciences Liverpool School of Tropical Medicine Pembroke Place Liverpool L3 5QA United Kingdom

E-mail: Penelope.Phillips-Howard@1stmed.ac.uk 